\section{Parents' reported responses to the disclosure of Down's syndrome}

\section{Elaine Herbert}

\author{
Institute of Education, \\ University of Warwick, \\ Coventry, U.K.
}

Few studies have centred on the reactions of fathers to the births of children with special needs, the majority have reported mothers' responses and their perceptions of the fathers' reactions and needs. Literature on the subject is sparse. This paper reports two studies which focused on the parents of ten pre-school children with Down's syndrome. These studies explored mothers' and fathers' responses to (i) the disclosure of diagnosis and (ii) the events during the six months following disclosure. Study 1 involves the mothers of these children and study 2 was carried out with the fathers of seven of these children. The studies were carried out by semi-structured personal interviews.

Some of the key issues raised by the fathers were the ways in which the diagnosis was disclosed, the initial and ongoing access and availability of professionals, the focus of services on mothers and children, their inability to discuss their feelings with their partners and their role as supporter.

\section{Acknowledgements}

To the mothers and fathers of the ten children who allowed me to speak to them and shared their recollections, to Dr Ann Lewis, Professor Tricia David and Barry Carpenter for their encouragement and support.

(C) 1993, 1999. The Down Syndrome Educational Trust Down Syndrome Research and Practice

1995, 3 (2) 39-44

\section{Introduction}

Amid the explosion of research into the role of the father within the family, little research has been carried out with the fathers of children with special needs (Meyer, 1986). McConachie (1986) suggests that a glaring omission from most previous research in parent: child interaction has been the part played by fathers. Most research findings are based on mothers' ideas about fathers' needs and very little is known about the reactions of fathers in these circumstances, particularly in the very early days following the birth (e.g. Hornby, 1991; McConachie, 1986; Rodrigue, Morgan and Gelfken, 1992). It has been assumed that what is good for the mother is good for the father.

Fathers have been identified as 'hard to reach' (McConkey, 1994), often due to their absence from the home during the day - the time when most professionals and researchers work. McConachie (1986) is aware that the roles of separate members of the family are likely to be obscured unless each is interviewed separately.

Most research literature available emanates from America, much of it involving the personal accounts of fathers of children with special needs (Hannam, 1988; Turnbull and Turnbull, 1985, 1986). These cannot be assumed to be representative of a wider group of fathers as the authors are not only able to compose the accounts but have also found the time to do so.

\section{Background to the studies}

This paper reports two studies which focused on the parents of 10 pre-school children with Down's syndrome. These studies explored mothers' and fathers' responses to (i) the disclosure of diagnosis and (ii) the events during the six months following disclosure. Study 1 involves the mothers of these children and study 2 was carried out with the fathers of seven of these children.

The mothers had been known to the author for between 18 months and two years through her work with the local PreSchool Education Service. Children with a wide range of learning difficulties are referred to the Service by a variety of agencies as well as by parents themselves. The Service comprises teachers who work in the home setting with the aim of enhancing the skills of parents and their children with special educational needs.

Parents are viewed as partners (Herbert, 1994) and the Service attempts to follow the 'consumer' approach advocated by Cunningham and Davis (1985). In the vast majority of homes, despite an aim for the Service to work with families and parents, the contact is generally between pre-school teacher, child and mother. Significant other family members are difficult usually to reach.

A large proportion of each home visit focuses on the preparation and evaluation of individual teaching programmes. Over time the relationship between the pre-school teachers and the mothers develops to allow them to share 'life histories' including the events surrounding the initial disclosure of diagnosis. It was as a result of these informal discussions that the author began to realise how unsatisfactory were many of the early contacts between these mothers and professionals or support agencies. This was particularly the case with the mothers of babies with Down's syndrome. 
Disclosure was often soon after the birth as Down's syndrome can be diagnosed at an early stage. The author therefore decided to look more closely at the experiences of these particular families in order to gain a clearer picture of events surrounding the disclosure of Down's syndrome and so to aid the development of the Service's interactions with families.

\section{Study 1}

\section{Method}

\section{Sample}

The target sample comprised the parents of ten children with Down's syndrome who were currently working with the author in the home setting. Nine of the ten parents were living in stable relationships. The ten children were aged between 3 and 4 at the time of the interviews. One of the ten children was adopted. It had been assumed by the author that in the nine families where it was possible, the interviews would involve both mother and father. However in every home but one, only the mother took part, despite the fact that the fathers were often at home. In the one home in which both parents took part, the child was adopted and the father, a paediatrician, was interested in the subject area from both a paternal and a professional outlook.

\section{Procedures}

The purpose and form of the research were explained to the mothers during a regular home visit when the mothers were invited to collaborate in the project. They were given a guarantee of confidentiality and anonymity at all stages. These were important given the continuing professional relationship between the family and the author.

A semi-structured interview schedule (see appendix) was prepared which covered the birth, disclosure of diagnosis and events of the following six months. Appointments were made to carry out the interviews in the homes. It was felt that the families would be relaxed in this situation. Eight of these interviews were arranged for weekday evenings and two for daytime weekends.

The interviews lasted between one and three hours. Responses were recorded in note form. The mothers exhibited a wide range of strong emotions; in two cases the mothers became so upset it was not possible to complete the schedule. Their recall of the specific events surrounding the disclosure of diagnosis was particularly clear. The mothers' descriptions highlighted feelings of 'chronic sorrow' (Olshansky, 1961; Wikler, 1984) and that the birth of their children had set them apart from other mothers.

\section{Findings}

Ten key points emerged from the findings of this study. Three concerned the mothers' emotions at the time of the disclosure:

(i) the disclosure of diagnosis could have been handled more effectively,

(ii) the mothers felt isolated at a very early stage, and

(iii) the mothers felt that their reactions were very different from their partners.

Three findings concerned the mothers' reactions and expe- riences in the period after disclosure:

(i) the mothers still experienced on-going and repetitive periods of vulnerability, grief and sorrow,

(ii) there was very little co-ordination between the professionals who worked with families,

(iii) the emotions exhibited by the mothers during the interviews had not been displayed to that depth during regular professional contacts with the author.

Four findings related to the role of the fathers:

(i) the mothers felt that their partners had difficulty in discussing many of the sensitive issues with them and with others, (ii) the information collected reflected only the mothers' perceptions of the fathers' reactions

(iii) there was little known of the reactions of fathers to the births of children with special needs,

(iv) the fathers had assumed that the project concerned their partners. The way in which the initial project had been set up, verbally with the mothers in the course of a home visit, may have created the false impression that the focus of the project involved only mothers. As the result of these findings, particularly the latter four points, the possibility of conducting a parallel study with the fathers of the same children was explored.

\section{STUDY 2}

Several questions needed addressing before Study 2 could be carried out:

1. Was it right to ask the fathers to discuss a topic which the mothers felt they had chosen to avoid for more than 3 years? 2. Was it right to ask the fathers to talk to someone outside the family, when they had difficulty in speaking to their partners?

3. Would the discussions evoke similar reactions to those exhibited by the mothers?

4. What support could be offered after the interviews, if the fathers needed it?

5. How would the researcher react if the fathers experienced distress similar to their partners when recalling the early events?

6. Would the discussions at a personal level interfere with future professional contacts with the fathers?

Whilst the author had training in active listening and had been a volunteer with a listening service for many years, there was an understanding that one may be opening wounds and then providing no ongoing support. Was this a responsible act?

One factor which influenced the responses to these questions was a realisation that the author had fallen into the same trap as others, that of taking the mothers' report of the fathers' reactions.

\section{Method}

\section{Sample}

The fathers in Study 2 were the fathers of the children involved in the original project. The sample available for the study was reduced to seven. This was due to the fact that the 
father of the adopted child had participated in the original research, one child was living with his mother alone and one family had left the area.

\section{Procedures}

The design of the second project allowed for the fathers to make a definite choice about participating. They were approached by letter, outlining the aims of the study and acknowledging the intrusion into their privacy. It also emphasised the academic nature of the study, the lack of information about fathers' reactions and that possible tangible benefits would result for future recipients of the Preschool Service. The fathers were invited to contact the author only if they wished to participate. Despite initial concerns, all seven approached agreed to take part, one father commenting that he would be happy to do so 'because he knew her' and another because 'she was not a prying researcher interested in research primarily for its own sake.'

It was decided that these interviews would follow the original schedule prepared for the partners and would be carried out in the homes, responses recorded in note form. All seven men were in full time employment, therefore appointments were made for the evenings, 'after eight o'clock when the children would be in bed' (Stan). Lack of opportunity for access to fathers during the day has been seen as a major factor in the dearth of information about their reactions (Collins, cited in Meyer, 1986). The author had assumed that these interviews would be short. As the men had never spoken to their partners at length about their reactions and feelings it was thought unlikely that they would talk for very long to a relative stranger.

Whilst the author's relationships with the mothers had been established over time, contacts with the fathers had been infrequent, either at formal meetings when the progress of the children had been the focus or when they were at home during breaks from work.

Despite the decision to proceed with the project, the initial concern highlighted by the author about the stress which may be induced when recalling the early diagnosis and consequent events had not been totally allayed. Therefore it was with some apprehension that the project proceeded. Lee has identified this type of contact as being 'emotionally charged,' often resulting in the interviewer being unable to maintain poise, and the interviewee sharing feelings of 'unease, discomfort or emotional pain' (Lee, 1993: 6).

At the outset of each interview, the fathers were given an assurance of anonymity and confidentiality and an undertaking to stop the questions at any time they chose. They all agreed to notes being taken of their responses.

Whilst it must be remembered that recollection of past events is influenced by selective memory (Murgatroyd, 1985) the fathers' accounts of the disclosure of diagnosis matched their partners in all aspects - the words used by the paediatrician, the positioning of staff within the room, the responses and reactions of themselves and their partners. Hannam (1988) has stated that whilst there can be no way of giving bad news well, there must be an optimum method and time. Cunningham and his co-workers at the Hester Adrian Centre in Manchester explored this to formulate a preferred way.

\section{Findings}

The findings will be discussed under two main themes: the diagnosis and first contacts with people outside the immediate family.

\section{The diagnosis}

The seven fathers had been present at the births and for all, this was a second or third child, therefore the events in the delivery room and in the hospital were within their experiences. The children were born in three different hospitals and the paediatrician attached to each hospital gave the diagnosis within the first 24 hours in six cases. In the seventh case, the news was broken as the family was about to leave for home, 3 days after the birth.

The style of delivery varied from the 'abrupt' to the 'sympathetic.' In two cases the words used conveyed a negative image of the children:

"I 've examined your baby and quite honestly I don't like the look of her. She has all the characteristics of Down's syndrome" (Steven),

and

"You may like to put the cot behind the bed for a while, so you won't see her" (Jack).

The 'anger' expressed by one father at the abrupt way in which the news was given was still clear in his description of the disclosure interview:

"We (my wife and I) were standing by the window when she came in. She sat on a chair and said, straight away, 'I've got some bad news for you. Your son's a mongol' - nothing leading up to it. I could have picked her (the paediatrician) up and thrown her through the window" (Tony).

He would have liked to complain to the hospital management but felt this "might jeopardise my son's ongoing treatment. They have guide-lines for double glazing salesmen, why not for this?" (Tony).

In six families the paediatrician told the parents together, in a private room, but in one case, the mother was told on her own prior to her partner's visit. She had detected from a combination of being moved to a side ward where she was on her own, plus the 'obvious discomfort of the nursing staff, that all was not well' (Gordon) and had asked directly if anything was wrong. The paediatrician was called and he told her immediately.

One father, who was very critical of the method of disclosure, felt he and his partner had not reached the necessary maturity to cope with the new situation: "We were like babies to be exposed to such news" (Tony). There was an acknowledgement that after the words 'Down's syndrome' (or 'mongol' in two cases) were spoken, the rest of the news was not heard:

"All I could hear was the voice droning on in the background, giving us information we did not need and could not hear'" (Graham).

During the initial interviews, the paediatrician also gave news of possible secondary complications such as heart 
defects, 'typical characteristics' or choices about taking the child home. These facts were in every case considered as 'too much, too soon': "We had only just heard the words Down `s syndrome, why tell us more?" (said individually by Graham, Tony, Gordon and Jack).

Four of the families left the hospital within hours of the disclosure to return to 'the security of home' and so were not able to extend their discussion with the paediatrician, but in three families further discussions took place the following day, which the fathers found 'useful and more informative' - although they felt the paediatrician was concentrating on their partners.

When recalling these events, two fathers cried. These same fathers also stated that they had cried with their partners at the time of disclosure. For the others, their immediate priority at the time of disclosure and in the following weeks appeared to be support for their partners.

\section{First contacts}

The fathers in the study were all living geographically close to their parents or siblings and these were the first people with whom the fathers shared the news. In this setting, they felt they received the emotional support they needed but, as they tried to explain what they had been told, immediately recognised their lack of knowledge and understanding about Down's syndrome.

News was given to close colleagues at work, to friends and to neighbours by telephone and whilst their responses were felt to be supportive the fathers felt, "they didn 't know how to handle what I was saying or what they should say to me" (Jack).

The first person to visit the family at home was often a medical professional. The GPs involved with this small group of fathers presented a pessimistic image of the future, taking the fathers to one side and forecasting: "She (the partner) may attempt suicide or harm the baby" (Tony) or "this may break up your marriage" (Steven). Health visitors appeared to have portrayed a lack of confidence in their responses, "never had a Down`s child before" (Jack) making the family feel isolated and 'different.' The fathers felt that whilst they were not excluded in discussions, contacts with visiting professionals were directed towards their partners; no one asked them about their reactions, but "how`s she taken it? how is she coping?" (Graham).

From these medical contacts, the families were often put in touch with other families with children with Down's syndrome. Whilst there is an acknowledgement of the benefits of such networking (Hornby, 1991), the need for sensitivity in setting up these contacts was continually highlighted. The fathers in three cases were immediately aware that the only thing they had in common with the contacts was the child's 'label' (Byrne et al. 1988). Nor were the families ready for either the over positive attitudes portrayed by some 'campaigners, making it out to be the best thing that was since sliced bread' (Tony) or the warnings of future difficulties.

For one father, these contacts had a very negative effect. His recollections were of being 'in a goldfish bowl, taken over' because his partner had given birth to twins, both of whom had Down's syndrome. They were contacted within days of the birth by a researcher who wanted to interview them because he said it was difficult to make contact with families with twins, both of whom had Down`s syndrome, and subsequently by another family who had also had twins and were themselves in great distress. These contacts in no way acted as a support but added to their own grief and not surprisingly they decided to 'keep ourselves to ourselves'.

The fathers were conscious of how others would perceive their children. One said that "only one person said anything at all about how she looked and that was the mother of a child with Down's syndrome" (Stan). One father said he had "spent a long time looking at his daughter waiting for her to turn into 'a mongol'" - for these were the words the paediatrician had used in the diagnosis, words which he finds very upsetting and distinctly offensive.

The need for relevant and up to date information about Down's syndrome was highlighted in every interview. The fathers had no prior knowledge of the condition and scoured the shelves of bookshops and the local libraries but either found nothing or found books 'giving gloomy forecasts of the future and anticipated difficulties.' Five were given the address of the Down's Syndrome Association and two made contact and received information from them. This they found more positive.

Whilst the fathers acknowledged their role as 'supporter' and of being competent in a crisis, within a short time every father returned to work. They felt that this would retain 'the normality in our lives'. The fathers all appeared to be aware of the differing reactions within the partnership, particularly with the passing of time. Whilst they felt their responses may have been the same at the time of disclosure, they assumed the role of supporter, 'the sturdy oak,' within a short time. This attitude had a decisive effect in one family where the decision to bring the baby home from hospital was taken by the father. "She was our baby, and we would look after her" (Jack). Another father commented: "I was driving home crying and suddenly I thought 'she's our child and we shall love her'" (Tony). In both these families, the fathers also acknowledge that their partners' adverse reaction continued for 'months.'

\section{Discussion}

Study 1 highlighted mothers' concerns about difficulties in discussing with their partners' feelings surrounding the birth of a child with Down's syndrome. Therefore there were anxieties for the author $(\mathrm{EH})$ about raising these issues with the fathers.

Consequently the first surprising outcome of Study 2 was the apparent warmth with which the fathers welcomed the author $(\mathrm{EH})$ and the lengthy duration of the interviews. Each of these interviews lasted for over two hours and all fathers involved appeared willing to share their recollections and experiences. Each one spoke of his difficulty in talking with his partner about the birth of the child with Down's syndrome. Three of these fathers said that it would have been useful to have had available a third person to encourage and facilitate discussion. The ease with which these fathers spoke may have reflected the researcher's previous involvement with the family as a member of an established early intervention team. She was known by the fathers to be valued by the mothers and the children.

Without exception, the fathers reported that their main role 
was that of support to their partners and, in some cases, to the extended family. None of the fathers mentioned their own feelings following the shock of the initial diagnosis. Each spoke of concern about how their partner felt when the news was broken. Whilst the fathers spoke of their outward distress immediately following the diagnosis, they also assumed the role expected of them by society, the 'sturdy oak'. The needs of their partners were recognised, acknowledged and, at least partly, addressed. Meanwhile the needs of the fathers took a second place. All supporting agencies centred on the mothers and babies. No one spoke with the fathers or addressed their concerns. Within a short while all information reached the fathers second-hand through their partners with the changes inherent in re-telling and reconstruction.

The fathers felt that they did not have a frame of reference in which to place their new baby. The gloomy forecasts of health personnel were thought of retrospectively as judgemental and outside the domain of those professionals. One father understandably commented on the acute need for customer relations in this context. McKinley (in press) has estimated that each GP will have one new patient with Down's syndrome in a career of over 30 years. However the good practice necessary in this situation is generalisable across a range of situations so infrequency of links with a parent of a child with Down's syndrome should not be used as an excuse for poor procedures.

All the fathers interviewed returned to work shortly after the birth. They felt that this would restore a sense of normality to their lives. The birth of the child was discussed with few, if any, work colleagues. If this was discussed, it was with immediate line managers only.

The children whose parents were involved in these interviews were all between ages 4 and 5 at the time of the interviews. All the fathers spoke of difficulties concerning imminent educational decisions. Many of the children were involved in preliminaries to the making of a statement. This had triggered in these fathers re-emerging feelings of vulnerability and 're-visiting the sorrow' (Gordon) felt during the child's early weeks of life. The process of formal assessment had reinforced the notion that these children were 'different,' needing to travel along different pathways from those of peers and siblings. The fathers felt that once again they had to assume the role of strong supporter as partners felt distressed by the statementing process.

\section{Conclusions}

This paper has reported two studies involving separate interviews with the mothers and fathers of children with Down's syndrome. It has attempted to redress omissions from other studies; that of accepting the mothers' accounts of fathers' reactions and needs. The fathers were interviewed alone and for each one this was the first time they had spoken at such length to anyone outside the family. They may be considered as being 'hard to reach' (McConkey, 1994) but all seven interviews undertaken demonstrated a willingness to share experiences and deeper emotions. Whilst there is an acknowledgement that these recollections may have been 'distorted through selective perception and selective remembering' (Murgatroyd, 1985, p 87) the author was conscious of the ease with which the men spoke and of their ongoing difficulty of discussing their feelings with their partners. This may be attributed to the fact that at last they felt someone was listening to them (Cunningham and Davis, 1985). A father, not involved in the original study, found key findings not only reinforced his own experiences and feelings but enabled him to reflect and refine his personal experiences (Herbert and Carpenter, 1994).

Lewis (1986) has suggested that all fathers must feel second class parents. For the fathers in the study, their early encounters, particularly with 'professionals,' will have reinforced this. For the professionals involved, the diagnosis and early days are worrying and difficult, for families this is only the beginning (Cunningham, 1988). Society expects men to assume the role of supporter and provider, and it may be that when confronted with a situation of excessive stress (Kennedy, 1981) fathers retreat into a frame of reference that they understand - that of being competent in a crisis and of providing strength in the relationship.

Researchers and support services have focused on mothers and children. Unless the needs of each member of exceptional families are acknowledged and addressed, fathers will continue to be overlooked.

One of the questions addressed by the author before embarking on the study was the possibility of offering support after the interviews took place. This did not happen; whether talking to someone outside the family had enabled the partners to discuss their child and concerns is unknown. The confidences were never mentioned again. The ongoing relationship between author and families continued and the personal discussions did not appear to interfere with the professional relationship, in fact it gave the author a greater understanding of the dynamics within the families and has had implications for all her future contacts. However, whilst the author gained an insight, what did these particular fathers gain? Was this the first and last time they were not 'hard-to reach'? (McConkey, 1994).

\section{Appendix}

\section{Semi structured interview schedule}

This was used as a "aide memoire" to ensure the same subject area was covered with each interviewee.

1. Can you remember much about the pregnancy?

2. Did the labour start at home or was your wife/partner in hospital?

3. What happened in the labour ward?

4. Who was there and what do you remember about them at the birth?

5. How were the nurses/midwife in the delivery room?

6. Was there a doctor there?

7. Can you remember what happened when you left there? Where did you go? Was the baby with you?

8. What happened then?

9. Do you remember who you spoke to?

10 Who suggested all was not well? How was this done?

11. Who told you?

12. Were they on their own?

13. Can you remember anything they said during these moments?

14. What did you do when you left your wife/partner in hospital? 
15. Where did you go?

16. Did you tell anyone - phone, contact? Can you remember what you said?

17. When did you go back to the hospital?

18. Did you see a nurse?

19. Did the paediatrician come to see you?

20. Did you ask any questions?

21. Did anyone visit?

23. What contact did you have with the nurses?

24. What contact did you have with the doctors?

25. Can you remember what happened when you went home with your wife/partner and baby?

26. Who called?

27. Did you see your GP?

28. Did you meet your health visitor?

29. What about your colleagues at work- did you talk to them?

30. When did you go back to work?

31. Did you find any books which were helpful?

32. Who do you think was the most helpful person?

\section{References}

Byrne,E.A., Cunningham,C.C. and Sloper,P.(1986).Families and their children with Down's Syndrome: One Feature in Common. London: Routledge.

Cunningham,C.C. and Davis,H.(1985). Working with Parents: Frame works for Collaboration, Milton Keynes: Open University Press.

Hannam,C.(1988). Parents and Mentally Handicapped Children. Bristol: Classical Press.

Herbert,E. (1994). Becoming a Special Family. In: T. David, Working together for Young Children. London: Routledge

Herbert,E. and Carpenter,B. (1994). Fathers the Secondary

Partners: Professional perceptions and a father's reflections. Children and Society, 8, (1) 31-41.

Hornby,G. (1991). Parental Involvement. In: Early Intervention Studies for Young Children with Special Needs. Norwich: Chapman Hall.

Kennedy,E. (1981). Crisis Counselling for Non-Professional Counsellors. Dublin: Gill and MacMillan.

Lee,R.M. (1993). Doing Research on Sensitive Topics. London: Sage Publications.
Lewis, C. (1985). Becoming a Father. Milton Keynes: Open University Press.

McConachie,H. (1986). Parents and Young mentally Handicapped Children: A Review of Research Issues. London: Croom Helm.

McConkey,R. (1994) Early Intervention: Planning futures, shaping years. Mental Handicap Research, 7 (1), 4-15.

McKinley,I. (In press). Disclosure of Developmental Disorders. Paper to the International Seminar on 'Partnership with Parents and Professionals in the Care of Children and Young Children with Learning Disabilities. 'December, 1994, UMIST, Manchester.

Meyer,D. (1986). The Father Role: Applied Perspectives. New York: John Cowley.

Murgatroyd,S. (1985). Counselling and Helping - Psychology in Action. Leicester: Methuen.

Olshansky,S. (1962). Chronic Sorrow: A Response to having a Mentally Defective Child. Social Casework, 43, 191194.

Rodrigue,J.R., Morgan,S.B. and Geffken,G.R. (1992). Psychological adaptation of fathers of children with Autism, Down's syndrome and normal development. Journal of Autism and Developmental Disorders, 22 (2) 249-263.

Turnbull,A.P. and Turnbull,H.R. (1986). Families, Professionals and Exceptionality: A Special Partnership. Columbus, Ohio: Merrill Publishing Company.

Turnbull,H,R and Turnbull, A.P. (1985). Parents Speak Out: Then and Now. Coumbus, Ohio: Merrill Publishing Company.

Wikler,L. (1984). Special Feelings of Special Families. In: Henniges and Neseelrood (Eds), Working with Parents of Handicapped Children. University of America: University Press of America.

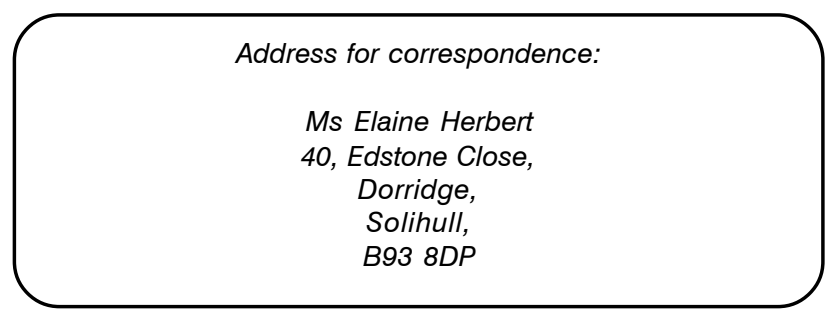

